\title{
Bidding strategy of wind-thermal energy producers
}

\author{
R. Laia ${ }^{\text {a, b }}$, H.M.I. Pousinho ${ }^{\text {, }}$, R. Melíco ${ }^{\text {a, b, * , V.M.F. Mendes }}{ }^{\text {b, c }}$ \\ ${ }^{a}$ IDMEC, Instituto Superior Técnico, Universidade de Lisboa, Av. Rovisco Pais 1, 1049-001 Lisbon, Portugal \\ b Departamento de Física, Escola de Ciências e Tecnologia, Universidade de Évora, R. Romão Ramalho 59, 7002-554 Évora, Portugal \\ ${ }^{\mathrm{c}}$ Department of Electrical Engineering and Automation, Instituto Superior de Engenharia de Lisboa, R. Conselheiro Emídio Navarro, 1950-062 Lisbon, \\ Portugal
}

\section{A R T I C L E I N F O}

\section{Article history:}

Received 8 February 2016

Received in revised form

30 May 2016

Accepted 20 July 2016

\section{Keywords:}

Bidding strategy

Stochastic programming

Mixed integer linear programming

Wind thermal coordination

\begin{abstract}
A B S T R A C T
This paper presents a stochastic mixed-integer linear programming approach for solving the selfscheduling problem of a price-taker thermal and wind power producer taking part in a pool-based electricity market. Uncertainty on electricity price and wind power is considered through a set of scenarios. Thermal units are modelled by variable costs, start-up costs and technical operating constraints, such as: forbidden operating zones, ramp up/down limits and minimum up/down time limits. An efficient mixed-integer linear program is presented to develop the offering strategies of the coordinated production of thermal and wind energy generation, having as a goal the maximization of profit. A case study with data from the Iberian Electricity Market is presented and results are discussed to show the effectiveness of the proposed approach.
\end{abstract}

(c) 2016 Elsevier Ltd. All rights reserved.

\section{Introduction}

Because of the negative environmental impact of fossil fuels and the desire to achieve energy independence [1], a number of countries have attempted to promote electricity generation from renewable resources by implementing various supporting mechanisms and policies to provide incentive or subsidy for renewable energy generation [2-4]. As the wind power technology matures and reaches breakeven costs, subsidies turn out to be less relevant and wind producers become interested in participating in electricity markets to maximize their profits [5]. Also, the incentives for renewable energy exploitation are feasible for modest penetration levels, but the incentives will become flawed as wind power penetration increases [6]. In 2014, 43.7\% of all new renewable installations were based on wind power and was the seventh year running that over $55 \%$ of all additional power capacity in the EU was renewable [7]. Despite the growing renewable energy integration worldwide in last decade [8], energy supply is still significantly dependent on fossil fuel since more than $60 \%$ of the electricity generated worldwide in 2012 was based on fossil fuel thermal plants [9].

\footnotetext{
* Corresponding author. IDMEC, Instituto Superior Técnico, Universidade de Lisboa, Av. Rovisco Pais 1, 1049-001 Lisbon, Portugal.

E-mail address: ruimelicio@gmail.com (R. Melíco).
}

In a deregulated electricity market, the generation companies (GENCOs) operate under a high competition degree due to the nodal variations of electricity prices [10] in order to obtain the best profit bidding in the day-ahead market [11]. For the wind power producers (WPP), wind power and the market-clearing electricity price uncertainties are to be addressed in order to know how much to produce in order to formulate realistic bids, because in case of excessive or moderate bids, other producers must reduce or increase production to fill the so-called deviation, implying penalties causing economic losses [12]. For thermal power producers, only market-clearing electricity price uncertainties have to be addressed.

This paper presents a formulation for GENCO owners of thermal plants and wind farms, which allows to submit electrical energy offers at the day-ahead market based on a profitable coordinated exploitation of wind power with thermal power.

\section{State of the art}

For the thermal producers, optimization methods to solve the unit commitment (UC) problem have been used since the old priorities list method [13-15] to the classical mathematical programming methods, like dynamic programming [16] and Lagrangian Relaxation [17,18] until the more recently reported artificial intelligence methods [19,20].

Although, easy to implement and requiring a small computation 
time, the priority list method does not ensure an economic convenient solution near a global optimal one, implying a higher operation cost [21]. Within the classical methods are included dynamic programming and Lagrangian relaxation-based techniques [22]. Dynamic programming methods are flexible but suffer from the "curse of dimensionality", due to the increase in the problem size related with the number of thermal units to be committed and the number of states considered for modelling the thermal behaviour of each unit during the time horizon, implying an eventually huge use of computation memory and processing time [23]. Although the Lagrangian relaxation [24] can overcome the previous limitation, does not always lead to a conveniently feasible solution, requiring the satisfaction of some violated constraints using heuristics in order to set a feasible solution, undermining the optimality. Artificial intelligence methods based on artificial neural networks [25], genetic algorithms [26], evolutionary algorithms [27] and simulating annealing [28] have also been applied. However, the major limitation of the artificial intelligence methods is the likelihood to obtain a convenient solution near global optimum, especially with a few thermal units.

Mixed integer linear programming (MILP) has been applied with success for solving the UC problem [29]. MILP is one of the most successful explored methods for scheduling activities because of rigorousness, flexibility and extensive modelling capability [30]. Although, nonlinear constraints have to be converted into linear ones by piecewise linear approximation, MILP allows an easily inclusion of new constraints that makes the problem formulation more appropriated to support the management decision.

For the WPP in a deregulated market, wind power and the market-clearing electricity price uncertainties are passed on the variables of the problems [31] to be addressed by the WPP in order to know how much to produce in order to formulate realistic bids. In order for upholding a WPP in a competitive environment, three main lines of action have been proposed in the technical literature: One of them is based on the use of wind power with energy storage technologies [32-34]; another one is the use of financial options as a tool for WPP to hedge against wind power uncertainty [35]; and the final one focuses on designing stochastic models intended to produce optimal offer strategies for WPP participating in an electricity market [36-39], without depending on third-parties or governmental regulations. The third line of action is a stochastic formulation explicitly modelling the uncertainties faced by the scheduling activities of a WPP [40], using uncertain measures and multiple scenarios built by wind power forecast [41-43] and market-clearing electricity price forecast [44-46] applications.

\section{Problem formulation}

\subsection{Market balancing}

Trading energy associated risks which must be taken in account in offering strategies. The risks are due to the uncertainties in available wind, energy prices and imbalance penalties. These uncertainties are addressed in the problem formulation.

System imbalance is the difference between the energy demand and the energy offer. The system imbalance is positive if there is an excess of generation in the power system, the system balance is negative if there is a deficit of generation in the power system.

The system operator seeks to minimize the system imbalance through a mechanism based on energy prices applied to the deviation of the energy produced by a producer and its energy offer in the day-ahead market. These prices, $\lambda_{t}^{+}$and $\lambda_{t}^{-}$, are applied in the balancing market to the energy deviations of the GENCO: $\lambda_{t}^{+}$is the price paid to the GENCO for its excess of generation and $\lambda_{t}^{-}$the price to be charged for its deficit.
If the system imbalance is negative, the system operator will keep the price of the day-ahead market, $\lambda_{t}^{D}$, for the energy in excess for those producers producing in excess of their offers, and will pay a premium price for the energy produced above the offer. If the system imbalance is positive, the system operator will keep the price of the day-ahead market for the energy in deficit for those producers producing in deficit of their offers (this is to be paid by the producers in deficit), and will pay for the energy in excess a price equal or lower than price of the day-ahead market. The applied prices to the deviations from the bids are explained in detail in [47].

The uncertainties in the available wind may result in differences between the energy traded by a GENCO with wind power and the actual energy generated. The revenue $R_{t}$ of the GENCO for hour $t$ is stated as:

$R_{t}=\lambda_{t}^{D} P_{t}^{o f f e r}+I_{t}$

In (1), $P_{t}^{\text {offer }}$ is the power traded by the GENCO in the day-ahead market and $I_{t}$ is the imbalance income resulting from the balancing process.

The total deviation for hour $t$ is stated as:

$\Delta_{t}=P_{t}^{a c t}-P_{t}^{o f f e r}$

where $P_{t}^{a c t}$ is the actual power for hour $t$.

If we define:

$r_{t}^{+}=\frac{\lambda_{t}^{+}}{\lambda_{t}^{D}}, \quad r_{t}^{+} \leq 1$

$r_{t}^{-}=\frac{\lambda_{t}^{-}}{\lambda_{t}^{D}}, \quad r_{t}^{-} \geq 1$

Then:

$I_{t}=\lambda_{t}^{D} r_{t}^{+} \Delta_{t}, \Delta_{t} \geq 0$

$I_{t}=\lambda_{t}^{D} r_{t}^{-} \Delta_{t}, \Delta_{t}<0$

A GENCO that needs to correct its energy deviations in the balancing market incurs an opportunity cost because in the dayahead market energy is traded at a more competitive price. The deviation in (2) will cause an imbalance cost given by:

$C_{t}=\lambda_{t}^{D}\left(1-r_{t}^{+}\right) \Delta_{t}, \Delta_{t} \geq 0$

$C_{t}=-\lambda_{t}^{D}\left(r_{t}^{-}-1\right) \Delta_{t}, \Delta_{t}<0$

The term $\lambda_{t}^{D} P_{t}^{\text {offer }}$ in (1) is the maximum revenue that the GENCO can collect from trading its energy in a situation without production uncertainty.

Because of the uncertainties, we will include a set of scenarios $\Omega$ for wind, energy prices and system imbalances. Each scenario $\omega$ will be weighted with its probability of occurrence $\pi$.

\subsection{Thermal production}

The operating $F_{\omega}$ it cost for a thermal unit can be stated as:

$F_{\omega i t}=A_{i} u_{\omega i t}+d_{\omega i t}+b_{\omega i t}+C_{i} z_{\omega i t} \quad \forall \omega, \quad \forall i, \quad \forall t$

The total operating cost in (9) is composed of four terms, 
namely: the fixed production cost, $A_{i}$, associated with the units operating at the minimum power, the added variable cost $d_{\omega}$ it part derived from the amount of fossil fuel consumed by the units, and the start-up and shut-down costs, $b_{\omega}$ it and $C_{i}$, of the units.

The typical non-differentiable and nonconvex functions used to quantify the variable costs of thermal units is replaced by piecewise linear approximations in order to use and to have the advantage of the stochastic MILP approach [1]. Hence, the variable cost function, $d_{\omega i t}$ is stated as:

$d_{\omega i t}=\sum_{l=1}^{L} F_{i}^{l} \delta_{\omega i \mathrm{t}}^{l} \quad \forall \omega, \quad \forall i, \quad \forall t$

$p_{\omega \text { i } t}=p_{i}^{\min } u_{\omega \text { i } t}+\sum_{l=1}^{L} \delta_{\omega \text { i } t}^{l} \quad \forall \omega, \quad \forall i, \quad \forall t$

$\left(T_{i}^{1}-p_{i}^{\min }\right) t_{\omega i t}^{1} \leq \delta_{\omega i t}^{1} \quad \forall \omega, \quad \forall i, \quad \forall t$

$\delta_{\omega i t}^{1} \leq\left(T_{i}^{1}-p_{i}^{\min }\right) u_{\omega i t} \quad \forall \omega, \quad \forall i, \quad \forall t$

$\left(T_{i}^{l}-T_{i}^{l-1}\right) t_{\omega i t}^{l} \leq \delta_{\omega i t}^{l} \quad \forall \omega, \quad \forall i, \quad \forall t, \quad \forall l$ $=2, \ldots, L-1$

$\delta_{\omega i t}^{l} \leq\left(T_{i}^{l}-T_{i}^{l-1}\right) t_{\omega i t}^{l-1} \quad \forall \omega, \quad \forall i, \quad \forall t, \quad \forall l$ $=2, \ldots, L-1$

$0 \leq \delta_{\omega i t}^{L} \leq\left(p_{i}^{\max }-T_{\omega i t}^{L-1}\right) t_{\omega i t}^{L-1} \quad \forall \omega, \quad \forall i, \quad \forall t$

The variable cost in (10) is the sum of the product of the slope of each segment, $F_{i}^{l}$ by the segment power $\delta_{\omega i}^{l}$. In (11), the power generation of the unit $i$ is given by the minimum power generation plus the sum of the segment powers associated with each segment. The binary variable $u_{\omega}$ it ensures that the power generation is equal to 0 if the unit $i$ is offline. In (12), if the binary variable $t_{\omega i \text { it }}^{l}$ has a null value, then the segment power $\delta_{\omega \text { it }}^{1}$ can be less than the segment 1 maximum power; otherwise and in conjunction with (13), if the unit is on, then $\delta_{\omega \text { it }}^{1}$ is equal to the segment 1 maximum power. In (14), from the second segment to the second last one, if the binary variable $t_{\omega i t}^{l}$ has a null value, then the segment power $\delta_{\omega i t}^{l}$ can be less than the segment $l$ maximum power; otherwise and in conjunction with (15), if the unit is on, then $\delta_{\omega \text { it }}^{l}$ is equal to the segment $l$ maximum power. In (16), the segment power must be between zero and the last segment maximum power.

The exponential nature of the start-up costs function, $b_{\omega \text { it }}$ is approximated by a linear formulation [2]. This linear formulation is stated as:

$b_{\omega i t} \geq K_{i}^{\beta}\left(u_{\omega i t}-\sum_{r=1}^{\beta} u_{\omega i t-r}\right) \quad \forall \omega, \quad \forall i, \quad \forall t$

$b_{\omega i t} \geq 0 \quad \forall \omega, \quad \forall i, \quad \forall t$

Notice that if the unit $i$ is online at hour $t$ and has been offline in $\beta$ preceding hours, the expression in parentheses in (17) is equal to 1, i.e., a start-up happen and the respective cost is considered.

The constraints to limit the power generated for each unit $i$ are stated as:

$$
\begin{aligned}
& p_{i}^{\min } u_{\omega i t} \leq p_{\omega i t} \leq p_{\omega i t}^{\max } \quad \forall \omega, \quad \forall i, \quad \forall t \\
& p_{\omega i t}^{\max } \leq p_{i}^{\max }\left(u_{\omega i t}-z_{\omega i t+1}\right)+S D z_{\omega i t+1} \quad \forall \omega, \quad \forall i, \quad \forall t
\end{aligned}
$$

$p_{\omega i t}^{\max } \leq p_{\omega i \mathrm{t}-1}^{\max }+R U u_{\omega i \mathrm{t}-1}+S U y_{\omega i t} \quad \forall \omega, \quad \forall i, \quad \forall t$

$p_{\omega i t-1}-p_{\omega i t} \leq R D u_{\omega i t}+S D z_{\omega i t} \quad \forall \omega, \quad \forall i, \quad \forall t$

In (18), the generating limits of the units are set. In (19) and (20), the upper bound of $p_{\omega i t}^{\max }$ is set, which is the maximum available power of the unit. This variable considers: unit's actual capacity, start-up/shut-down ramp rate limits, and ramp-up limit. In (22), the ramp-down and shut-down ramp rate limits are considered. In (20)-(22), the relation between the start-up and shut-down variables of the unit are given, using binary variables and their weights.

The minimum down time constraint is imposed by a linear formulation stated as:

$\sum_{t=1}^{J_{i}} u_{\omega i t}=0 \quad \forall \omega, \quad \forall i$

$$
\begin{aligned}
\sum_{t=k}^{k+D T_{i}-1}\left(1-u_{\omega i t}\right) & \geq D T_{i} z_{\omega i t} \quad \forall \omega, \quad \forall i, \quad \forall k \\
& =J_{i}+1 \ldots T-D T_{i}+1
\end{aligned}
$$

$$
\sum_{t=k}^{T}\left(1-u_{\omega i t}-z_{\omega i t}\right) \geq 0 \quad \forall \omega, \quad \forall i, \quad \forall k
$$$$
=T-D T_{i}+2 \ldots T
$$

$J_{i}=\min \left\{T,\left(D T_{i}-s_{\omega i 0}\right)\left(1-u_{\omega i 0}\right)\right\}$

If the minimum down time has not been achieved (33) ensures that the unit remains offline at hour 0 . In (24), the minimum down time will be satisfied for all the possible sets of consecutive hours of size $D T_{i}$. In (25), the minimum down time will be satisfied for the last $D T_{i}-1$ hours.

The minimum up time constraint is also imposed by linear formulation stated as:

$$
\sum_{t=1}^{N_{i}}\left(1-u_{\omega i t}\right)=0 \quad \forall \omega, \quad \forall i
$$

$$
\begin{aligned}
\sum_{t=k}^{k+U T_{i}-1} u_{\omega i t} & \geq U T_{i} y_{\omega} \text { it } \quad \forall \omega, \quad \forall i, \quad \forall k \\
& =N_{i}+1 \ldots T-U T_{i}+1
\end{aligned}
$$

$\sum_{t=k}^{T}\left(u_{\omega i t}-z_{\omega i t}\right) \geq 0 \quad \forall \omega, \quad \forall i, \quad \forall k=T-U T_{i}+2 \ldots T$

$N_{i}=\min \left\{T,\left(U T_{i}-U_{\omega i}\right) u_{\omega} i_{0}\right\}$

If the minimum up time has not been achieved, (36) ensures that the unit remains online at hour 0 . In (27), the minimum up 
time will be satisfied for all the possible sets of consecutive hours of size $U T_{i}$. In (28), the minimum up time will be satisfied for the last $U T_{i}-1$ hours.

The relation between the binary variables to identify start-up, shutdown and forbidden operating zones is stated as:

$y_{\omega i t}-z_{\omega i t}=u_{\omega i t}-u_{\omega i t-1} \quad \forall \omega, \quad \forall i, \quad \forall t$

$y_{\omega i t}+z_{\omega i t} \leq 1 \quad \forall \omega, \quad \forall i, \quad \forall t$

The total power generated the thermal units is stated as:

$p_{\omega t}^{g}=\sum_{i=1}^{I} p_{\omega i t} \quad \forall \omega, \quad \forall t$

The total operating costs, $F_{\omega t}^{T}$ of the thermal units is stated as:

$F_{\omega t}^{T}=\sum_{i=1}^{I} F_{\omega i t} \quad \forall \omega, \quad \forall t$

\subsection{Objective function}

The offer submitted by the GENCO is the sum of the power offered from the thermal units and the power offered from the wind farm. The offer is stated as:

$p_{\omega t}^{o f f e r}=p_{\omega t}^{t h}+p_{\omega t}^{D} \quad \forall \omega, \quad \forall t$

The actual power produced by the GENCO is the sum of the power generated by the thermal units and the power generated by the wind farm. The actual power is stated as:

$p_{\omega t}^{a c t}=p_{\omega t}^{g}+p_{\omega t}^{\omega d} \quad \forall \omega, \quad \forall t$

In (34), $p_{\omega t}^{g}$ is the actual power generated by the thermal units and $p_{\omega t}^{\omega d}$ is the actual power generated by the wind farm for scenario $\omega$.

For a $24 \mathrm{~h}$ period the expected revenue of the GENCO is stated as:

$$
\begin{aligned}
& \sum_{\omega=1}^{N_{\Omega}} \sum_{t=1}^{N_{T}} \pi_{\omega}\left[\left(\lambda_{\omega t}^{D} P_{\omega t}^{o f f e r}+\lambda_{\omega t}^{D} r_{\omega t}^{+} \Delta_{\omega t}^{+}-\lambda_{\omega t}^{D} r_{\omega t}^{-} \Delta_{\omega t}^{-}\right)\right. \\
& \left.-F_{\omega t}^{T}\right] \quad \forall \omega, \quad \forall t
\end{aligned}
$$

Subject to:

$$
\begin{aligned}
& 0 \leq p_{\omega t}^{o f f e r} \leq p_{\omega t}^{M} \quad \forall \omega, \quad \forall t \\
& \Delta_{t \omega}=\left(p_{\omega t}^{a c t}-p_{\omega t}^{o f f e r}\right) \quad \forall \omega, \quad \forall t
\end{aligned}
$$

$\Delta_{t \omega}=\Delta_{t \omega}^{+}-\Delta_{t \omega}^{-} \quad \forall \omega, \quad \forall t$

$0 \leq \Delta_{t \omega}^{+} \leq P_{t \omega} d_{t} \quad \forall \omega, \quad \forall t$

In (36), $p_{\omega t}^{M}$ is maximum available power, limited by the sum of the installed capacity in the wind farm, $p^{E m a x}$, with the maximum thermal production. The maximum available power is stated as:

$p_{\omega t}^{M}=\sum_{i=1}^{I} p_{\omega i t}^{\max }+p^{E \max } \quad \forall \omega, \quad \forall t$

Some system operators require non-decreasing offers to be submitted by GENCO. This new constraint for equation (35) is stated as:

$$
\left(p_{\omega t}^{\text {offer }}-p_{\omega^{\prime} t}^{\text {offer }}\right)\left(\lambda_{\omega t}^{D}-\lambda_{\omega^{\prime} t}^{D}\right) \geq 0 \quad \forall \omega, \omega^{\prime}, \quad \forall t
$$

\section{Case study}

The effectiveness of the proposed stochastic MILP approach is illustrated by a case study using one set of data from the Iberian electricity market, comprising 10 days of June 2014 [28].

The market data is to be used by a GENCO that owns both thermal and wind production. For the thermal generation are considered 8 units with a total installed capacity of $1440 \mathrm{MW}$ and wind farm installed capacity is $360 \mathrm{MW}$. In a first step, we obtained the results for the described installed capacities and then we change the capacities first for the wind farm and then for the thermal units and investigate the gain variation of the coordinated approach versus the uncoordinated approach.

The eight thermal unit data, minimum/maximum power, ramp up/down values, start-up and shut-down ramp rate values, minimum up/down time, fixed and shut-down costs are shown in Table 1.

The variable costs of the thermal units have been modelled through piecewise linear approximations with three segments. Also, the start-up costs are modelled through stepwise approximations with ten intervals, as shown in Table 2.

The energy prices and the energy produced from wind are shown in Fig. 1.

The energy produced is obtained using the total energy produced from wind scaled to the maximum power of the installed capacity in the wind farm, $360 \mathrm{MW}$.

The system operator seeks to match the total energy production to the system needs. This is achieved by defining the price multipliers given by $r_{t}^{+}$and $r_{t}^{-}$. These price multipliers are shown in Table 3 and in Table 4.

The expected results for two different approaches, with and without coordination, are shown in Table 5.

The uncoordinated approach implies that two bids have to be submitted independently, one for the wind farm plant and other for the thermal plant. While the coordinated approach has only one bid to be submitted, having an expected profit higher. Also, the coordinated approach does not represent a burden in computational resources when compared with the uncoordinated one. The execution time measured by Gams is about the same for both approaches, since the wind execution time is irrelevant when compared with the thermal execution time in the uncoordinated approach. In the coordinated approach, the wind part is again irrelevant since the execution time for thermal uncoordinated is almost the same as the coordinated execution time.

The energies traded for each scenario, with and without coordination, are sown in Fig. 2 and in Fig. 3.

The weight of the wind in the total energy traded, with and without coordination, is shown in Fig. 4.

For the thermal part of the energy, the weight of the energy traded on the actual energy considered for the cost is shown in Fig. 5.

The actual energy is the energy considered for the thermal cost and is subjected to the technical constraints of the thermal plants. The offered energy, is only limited by the sum of the maximum possible energy generated by each thermal unit, $p_{\omega t}^{\text {th }}$.

Most energy markets require non decreasing energy offers. The non-decreasing energy offers for hour 5 and hour 15 are shown in Fig. 6. 
Table 1

Thermal units' characteristics.

\begin{tabular}{|c|c|c|c|c|c|c|c|c|c|c|}
\hline Unit & $p_{i}^{\min }(\mathrm{MW})$ & $p_{i}^{\max }(\mathrm{MW})$ & $R U_{i}(\mathrm{MW})$ & $R D_{i}(\mathrm{MW})$ & $S U_{i}(\mathrm{MW})$ & $S D_{i}(\mathrm{MW})$ & $U T_{i}(\mathrm{~h})$ & $D T_{i}(\mathrm{~h})$ & $A_{i}($ Eur $/ \mathrm{h})$ & $C_{i}($ Eur $/ \mathrm{h})$ \\
\hline U1 & 70 & 125 & 45 & 40 & 100 & 95 & 5 & 4 & 2900 & 170 \\
\hline $\mathrm{U} 2$ & 110 & 160 & 60 & 50 & 125 & 140 & 8 & 4 & 3150 & 215 \\
\hline U3 & 60 & 125 & 55 & 55 & 90 & 80 & 5 & 3 & 3060 & 120 \\
\hline U4 & 90 & 170 & 40 & 60 & 100 & 100 & 6 & 3 & 2995 & 155 \\
\hline U6 & 90 & 170 & 40 & 60 & 100 & 100 & 6 & 3 & 2995 & 155 \\
\hline U6 & 80 & 145 & 35 & 40 & 90 & 105 & 9 & 6 & 3225 & 120 \\
\hline U7 & 145 & 215 & 45 & 70 & 160 & 170 & 6 & 4 & 3810 & 110 \\
\hline U8 & 220 & 330 & 70 & 60 & 230 & 245 & 10 & 6 & 4490 & 135 \\
\hline
\end{tabular}

Table 2

Stepwise approximations of the start-up costs (Eur/h).

\begin{tabular}{|c|c|c|c|c|c|c|c|c|c|c|}
\hline Unit capacity (MW) & $K_{i}^{1}$ & $K_{i}^{2}$ & $K_{i}^{3}$ & $K_{i}^{4}$ & $K_{i}^{5}$ & $K_{i}^{6}$ & $K_{i}^{7}$ & $K_{i}^{8}$ & $K_{i}^{9}$ & $K_{i}^{10}$ \\
\hline$<125$ & 654 & 1347 & 1896 & 2254 & 2533 & 2684 & 2733 & 2767 & 2813 & 2853 \\
\hline$\geq 125$ and $\leq 215$ & 1046 & 2155 & 3034 & 3606 & 4053 & 4294 & 4373 & 4427 & 4501 & 4565 \\
\hline$>215$ & 2224 & 4580 & 6446 & 7664 & 8612 & 9126 & 9292 & 9408 & 9564 & 9700 \\
\hline
\end{tabular}
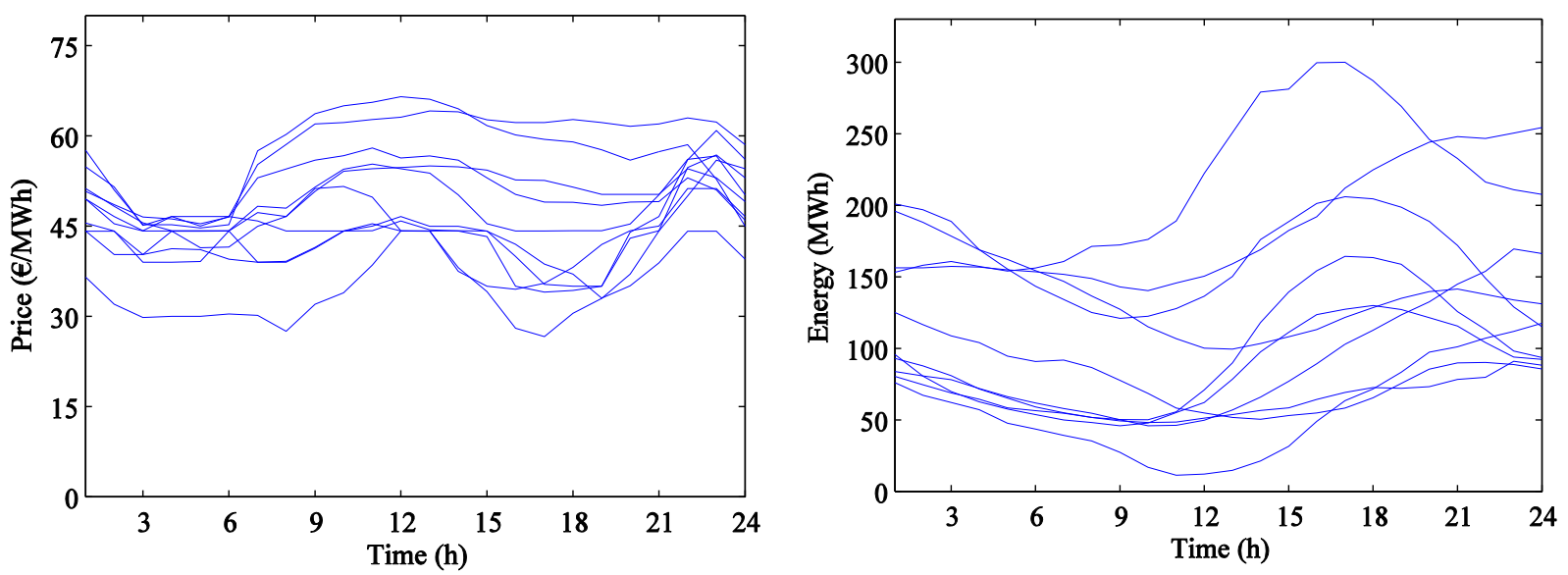

Fig. 1. Iberian market June 2014 (ten days); left: energy price, right: energy from wind.

Table 3

Price multipliers, system long.

\begin{tabular}{lllllllllll}
\hline \multirow{2}{*}{ Time $(\mathrm{h})$} & \multicolumn{2}{l}{ Scenario $r_{t}^{+}$} & & & & & & & & \\
\cline { 2 - 11 } & 1 & 2 & 3 & 4 & 5 & 6 & 7 & 8 & 9 & 10 \\
\hline 1 & 0.75 & 1.00 & 1.00 & 0.70 & 1.00 & 1.00 & 1.00 & 1.00 & 1.00 & 1.00 \\
2 & 1.00 & 1.00 & 1.00 & 0.80 & 1.00 & 1.00 & 1.00 & 1.00 & 1.00 & 1.00 \\
3 & 0.00 & 1.00 & 1.00 & 1.00 & 1.00 & 0.76 & 1.00 & 1.00 & 1.00 & 1.00 \\
4 & 0.00 & 1.00 & 1.00 & 1.00 & 1.00 & 0.47 & 1.00 & 1.00 & 1.00 & 1.00 \\
5 & 0.00 & 1.00 & 1.00 & 1.00 & 1.00 & 0.63 & 1.00 & 1.00 & 1.00 & 1.00 \\
6 & 0.00 & 1.00 & 1.00 & 1.00 & 1.00 & 0.70 & 1.00 & 1.00 & 1.00 & 1.00 \\
7 & 0.00 & 0.59 & 1.00 & 1.00 & 1.00 & 0.74 & 0.79 & 1.00 & 1.00 & 1.00 \\
8 & 0.00 & 1.00 & 1.00 & 0.53 & 1.00 & 1.00 & 0.72 & 1.00 & 1.00 & 1.00 \\
9 & 1.00 & 0.79 & 1.00 & 0.52 & 1.00 & 1.00 & 1.00 & 1.00 & 1.00 & 1.00 \\
10 & 1.00 & 0.66 & 0.63 & 0.68 & 1.00 & 1.00 & 1.00 & 1.00 & 1.00 & 0.23 \\
11 & 1.00 & 0.74 & 0.39 & 0.00 & 0.01 & 1.00 & 0.66 & 1.00 & 1.00 & 1.00 \\
12 & 1.00 & 0.76 & 0.72 & 0.15 & 0.00 & 1.00 & 0.70 & 1.00 & 1.00 & 1.00 \\
13 & 1.00 & 1.00 & 0.80 & 0.23 & 0.29 & 1.00 & 0.08 & 1.00 & 1.00 & 1.00 \\
14 & 1.00 & 1.00 & 0.78 & 0.21 & 1.00 & 1.00 & 0.01 & 1.00 & 1.00 & 1.00 \\
15 & 1.00 & 1.00 & 0.63 & 0.20 & 1.00 & 1.00 & 0.01 & 1.00 & 1.00 & 1.00 \\
16 & 1.00 & 1.00 & 0.78 & 1.00 & 1.00 & 1.00 & 0.65 & 1.00 & 1.00 & 1.00 \\
17 & 1.00 & 1.00 & 0.75 & 1.00 & 1.00 & 0.00 & 0.70 & 1.00 & 1.00 & 1.00 \\
18 & 1.00 & 1.00 & 1.00 & 1.00 & 1.00 & 0.00 & 0.53 & 1.00 & 1.00 & 1.00 \\
19 & 1.00 & 1.00 & 0.74 & 1.00 & 1.00 & 0.01 & 0.79 & 1.00 & 1.00 & 1.00 \\
20 & 1.00 & 1.00 & 0.65 & 1.00 & 1.00 & 0.11 & 0.55 & 1.00 & 1.00 & 1.00 \\
21 & 1.00 & 1.00 & 0.75 & 0.67 & 1.00 & 1.00 & 1.00 & 1.00 & 1.00 & 1.00 \\
22 & 1.00 & 1.00 & 0.56 & 1.00 & 1.00 & 1.00 & 1.00 & 1.00 & 1.00 & 1.00 \\
23 & 1.00 & 1.00 & 0.59 & 1.00 & 1.00 & 1.00 & 0.64 & 1.00 & 1.00 & 1.00 \\
24 & 1.00 & 1.00 & 0.80 & 1.00 & 1.00 & 1.00 & 1.00 & 1.00 & 1.00 & 1.00 \\
\hline & & & & & & & & & &
\end{tabular}

Table 4

Price multipliers, system short.

\begin{tabular}{|c|c|c|c|c|c|c|c|c|c|c|}
\hline \multirow[t]{2}{*}{ Time (h) } & \multicolumn{10}{|c|}{ Scenario $r_{t}^{-}$} \\
\hline & 1 & 2 & 3 & 4 & 5 & 6 & 7 & 8 & 9 & 10 \\
\hline 1 & 1.00 & 1.32 & 1.25 & 1.00 & 1.14 & 1.00 & 1.08 & 1.17 & 1.24 & 1.31 \\
\hline 2 & 1.25 & 1.19 & 1.32 & 1.00 & 1.07 & 1.00 & 1.15 & 1.17 & 1.43 & 1.12 \\
\hline 3 & 1.00 & 1.28 & 1.28 & 1.00 & 1.11 & 1.00 & 1.17 & 1.34 & 1.55 & 1.17 \\
\hline 4 & 1.00 & 1.17 & 1.19 & 1.01 & 1.02 & 1.00 & 1.07 & 1.38 & 1.50 & 1.04 \\
\hline 5 & 1.00 & 1.10 & 1.21 & 1.00 & 1.10 & 1.00 & 1.00 & 1.47 & 1.60 & 1.00 \\
\hline 6 & 1.00 & 1.08 & 1.24 & 1.00 & 1.05 & 1.00 & 1.00 & 1.53 & 1.65 & 1.10 \\
\hline 7 & 1.00 & 1.00 & 1.19 & 1.00 & 1.12 & 1.00 & 1.00 & 1.26 & 1.24 & 1.04 \\
\hline 8 & 1.00 & 1.00 & 1.21 & 1.00 & 1.03 & 1.00 & 1.00 & 1.28 & 1.17 & 1.09 \\
\hline 9 & 1.32 & 1.00 & 1.00 & 1.00 & 1.02 & 1.02 & 1.11 & 1.23 & 1.11 & 1.00 \\
\hline 10 & 1.23 & 1.00 & 1.00 & 1.00 & 1.00 & 1.09 & 1.14 & 1.23 & 1.13 & 1.00 \\
\hline 11 & 1.00 & 1.00 & 1.00 & 1.00 & 1.00 & 1.26 & 1.00 & 1.22 & 1.13 & 1.27 \\
\hline 12 & 1.00 & 1.00 & 1.00 & 1.00 & 1.00 & 1.02 & 1.00 & 1.20 & 1.14 & 1.22 \\
\hline 13 & 1.04 & 1.17 & 1.00 & 1.00 & 1.00 & 1.00 & 1.00 & 1.18 & 1.16 & 1.53 \\
\hline 14 & 1.13 & 1.00 & 1.00 & 1.00 & 1.27 & 1.00 & 1.00 & 1.16 & 1.19 & 1.43 \\
\hline 15 & 1.09 & 1.01 & 1.00 & 1.00 & 1.39 & 1.03 & 1.00 & 1.20 & 1.22 & 1.26 \\
\hline 16 & 1.16 & 1.04 & 1.00 & 1.32 & 1.39 & 1.17 & 1.00 & 1.20 & 1.26 & 1.26 \\
\hline 17 & 1.22 & 1.09 & 1.00 & 1.23 & 1.46 & 1.00 & 1.00 & 1.20 & 1.32 & 1.33 \\
\hline 18 & 1.29 & 1.22 & 1.14 & 1.38 & 1.19 & 1.00 & 1.00 & 1.20 & 1.33 & 1.22 \\
\hline 19 & 1.14 & 1.29 & 1.00 & 1.23 & 1.21 & 1.00 & 1.00 & 1.19 & 1.39 & 1.34 \\
\hline 20 & 1.05 & 1.23 & 1.00 & 1.09 & 1.10 & 1.00 & 1.00 & 1.16 & 1.43 & 1.26 \\
\hline 21 & 1.00 & 1.23 & 1.00 & 1.00 & 1.00 & 1.00 & 1.29 & 1.14 & 1.36 & 1.29 \\
\hline 22 & 1.05 & 1.13 & 1.00 & 1.26 & 1.07 & 1.14 & 1.20 & 1.16 & 1.34 & 1.25 \\
\hline 23 & 1.00 & 1.22 & 1.00 & 1.26 & 1.00 & 1.02 & 1.00 & 1.21 & 1.52 & 1.61 \\
\hline 24 & 1.00 & 1.23 & 1.00 & 1.30 & 1.00 & 1.00 & 1.19 & 1.25 & 1.69 & 1.42 \\
\hline
\end{tabular}


Table 5

Results with and without coordination.

\begin{tabular}{|c|c|c|c|}
\hline Case & Expected profit $(€)$ & Imbalance cost $(€)$ & Execution time (s) \\
\hline Wind uncoordinated & 119200 & -17826 & 0.02 \\
\hline Thermal uncoordinated & 516848 & 229398 & 0.13 \\
\hline Sum uncoordinated wind and thermal & 636048 & & 0.15 \\
\hline Coordinated Wind and thermal & 642326 & 3643 & 0.13 \\
\hline Gain $(\%)$ & 0.99 & & \\
\hline
\end{tabular}

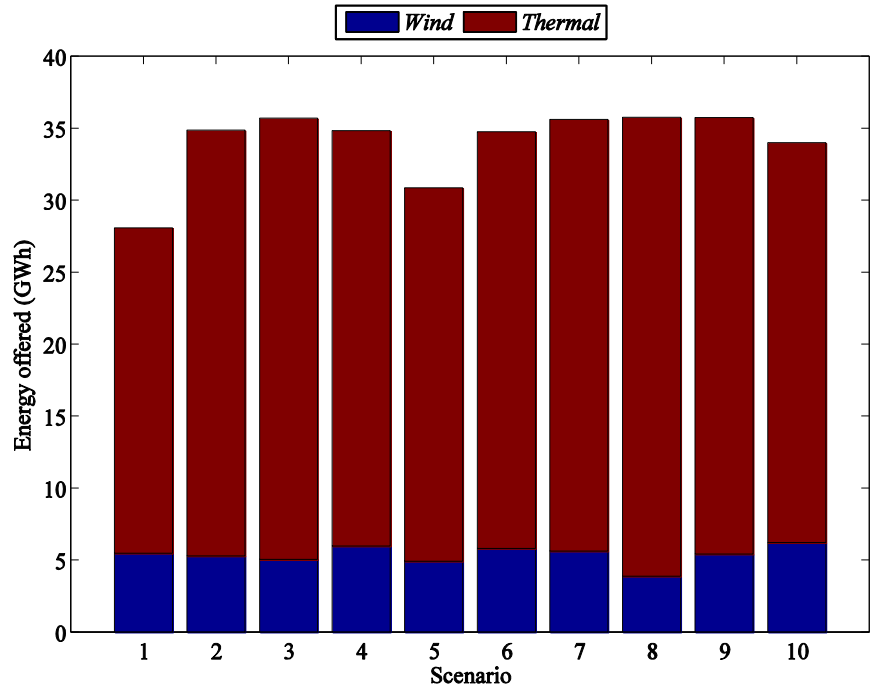

Fig. 2. Energy traded with coordination.

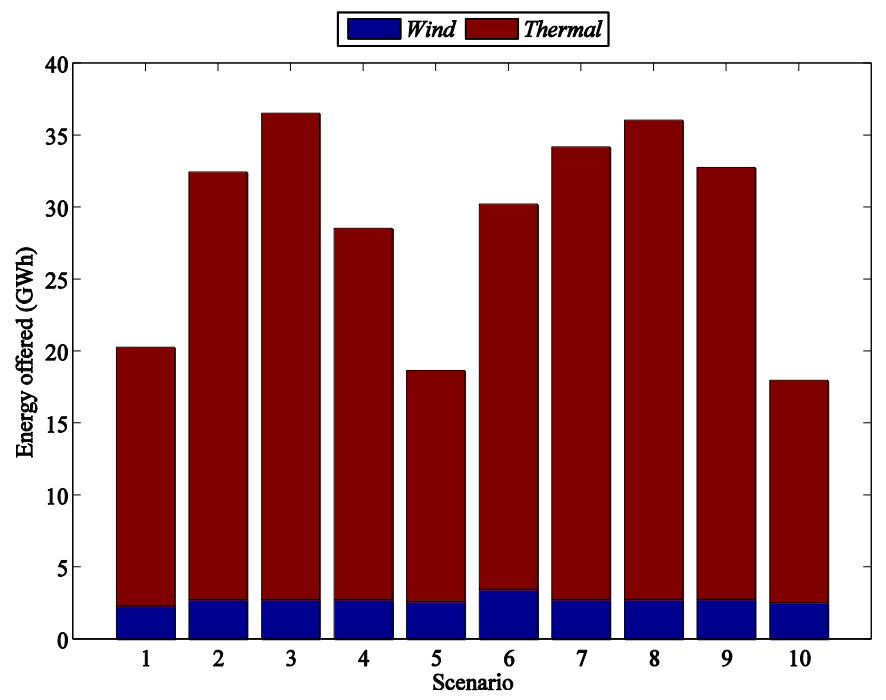

Fig. 3. Energy traded without coordination.

For the uncoordinated approach both wind and thermal bids are submitted for each hour, which means that each individual bid has to be non-decreasing. The total curve for hour 5 and hour 15 are the sum of the wind and thermal bids.

For the coordinated approach, only a bid is submitted for each hour. In Fig. 6 is represented the contribution of the wind and thermal generation for the energy to bid. Since only the energy to bid has to be non-decreasing, the wind and thermal contributions

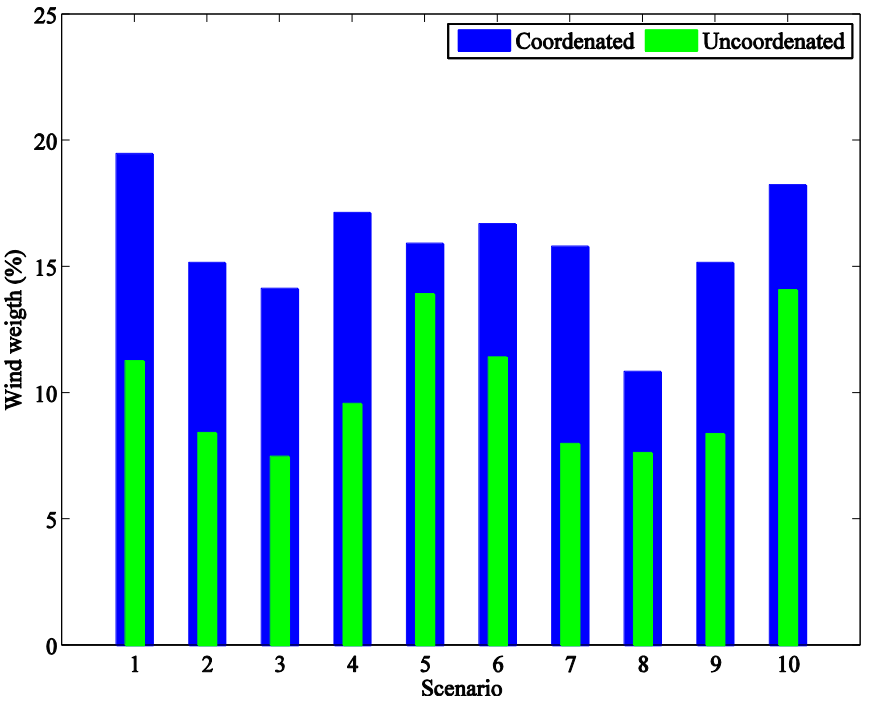

Fig. 4. Wind weight with and without coordination.

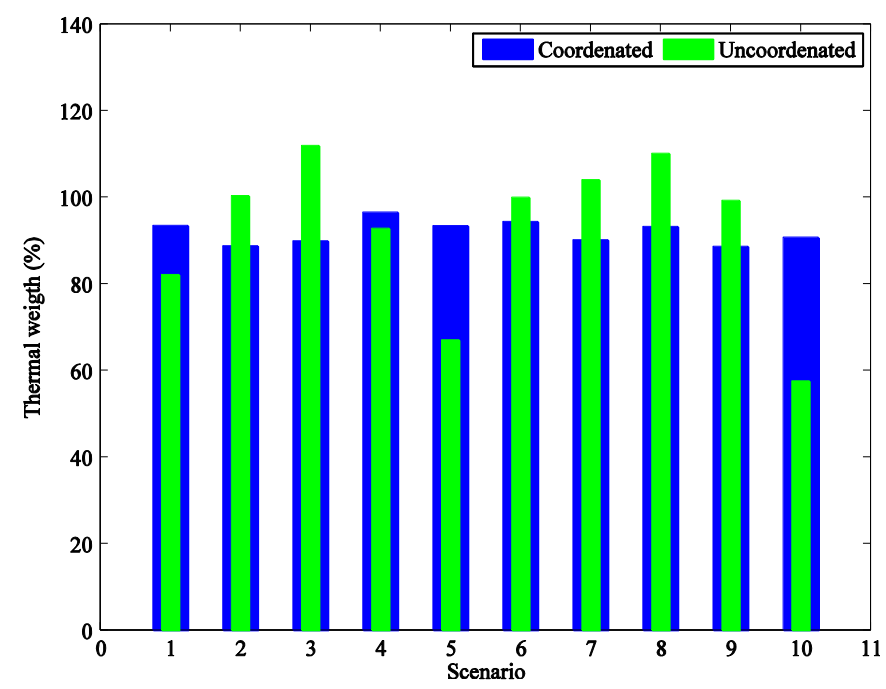

Fig. 5. Weight of the energy traded on the actual energy, thermal part.

don't have to be non-decreasing. This is the case for hour 15 .

The energy offer and committed for scenario 3 and scenario 10 are shown in Fig. 7.

In Fig. 7 we can see that wind parcel of the energy offer is higher for the coordinated approach for both scenarios, what is in accordance with Fig. 4. For the coordinated approach the thermal bid behaviour tends to be the opposite of the wind behaviour: when the wind parcel of the energy offer increases, the thermal parcel of 

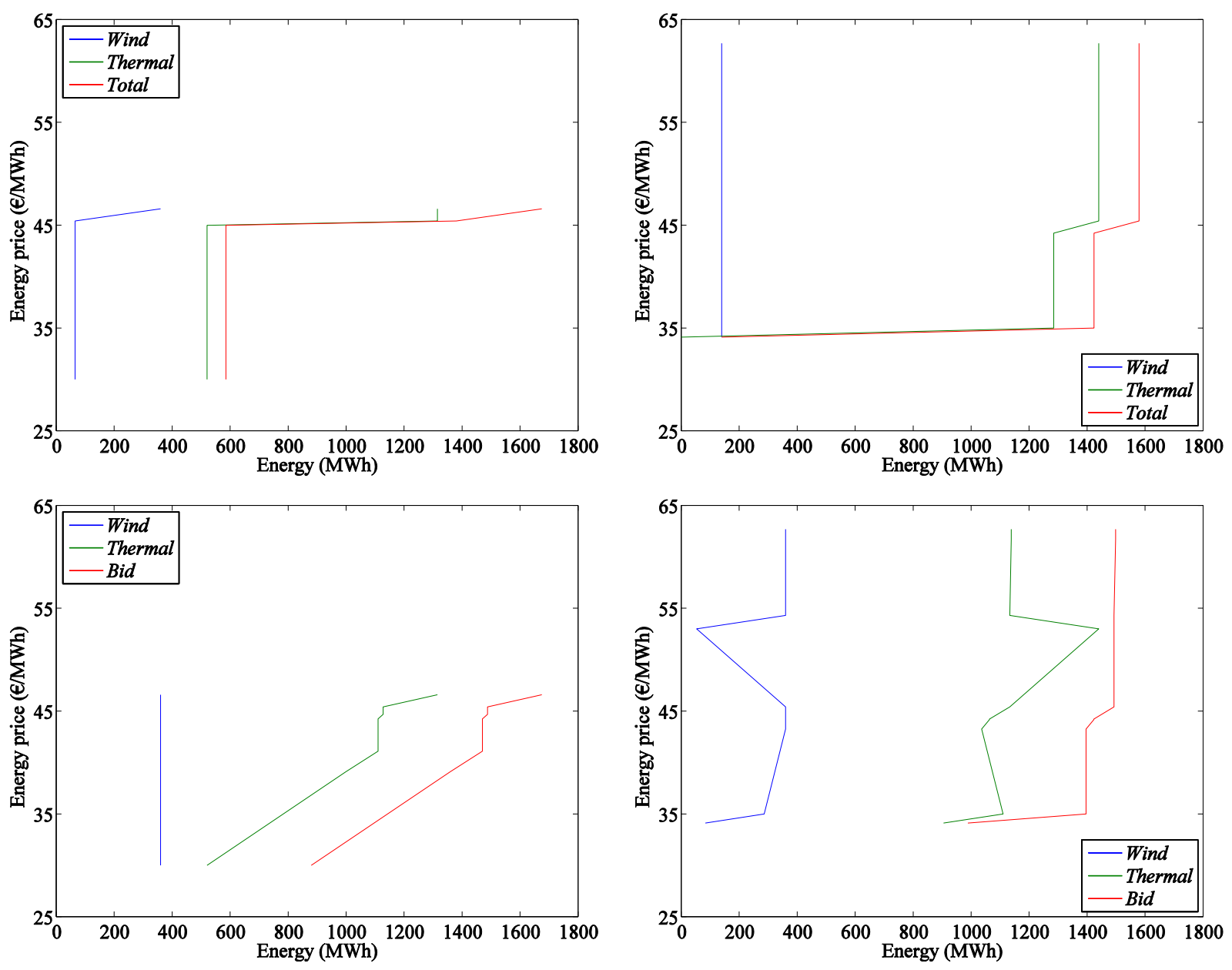

Fig. 6. Bidding energy offers. Top: uncoordinated; bottom: coordinated. Left: hour 5, right: hour 15.

the energy offer decreases, when the wind parcel of the energy offer decreases, the thermal parcel of the energy offer increases. The higher values of the wind parcel of the energy offer for the coordinated approach when compared with the uncoordinated approach is compensated in the coordinated approach by the decreasing of the thermal parcel of the energy offer, so the imbalance is minimized.

The expected gain results for the two different approaches, with and without coordination, are shown in Table 6 as a function of the wind farm capacity, keeping constant the thermal units installed power at $1440 \mathrm{MW}$.

The results expressed in Table 6 are for the same thermal units and the same scenarios of Table 5. The gain is dependent of the ratio between the wind farm and the thermal units. The maximum, $2.03 \%$, is achieved when the wind farm capacity is about 1.5 times the thermal units installed capacity.

The expected gain results for the two different approaches, with and without coordination, are shown in Table 7 as a function of the thermal units installed power, keeping constant the wind farm installed power at $360 \mathrm{MW}$.

The results expressed in Table 7 are for a wind farm capacity of $360 \mathrm{MW}$. For the thermal units installed power, the engineering units expressed in [MW] in Table 1 were scaled down by the same ratio of the thermal units capacity in Table 7 and $1440 \mathrm{MW}$. The same operation was performed on the ramp start-up costs. The gain is dependent of the ratio between the wind farm and the thermal units. The maximum, $3.20 \%$, is achieved when the thermal units installed capacity is about 2.3 times the wind farm installed capacity.

\section{Conclusions}

A stochastic MILP approach for solving the offering strategy and the self-scheduling problem of a price-taker wind power and thermal power producer is developed in this paper. The main results are the short-term bidding strategies and the optimal schedule of the thermal units. A mixed-integer linear formulation is used to model the main technical and operating characteristics of thermal units.

The coordinated offer of wind power with thermal power allows to provide better results than the sum of the isolated offers. But the results concerning the indirect objective function, the developed function, parametrized in function of the power capacities of the wind farm and of the thermal units are dependent of the ratio between these capacities. So, in order to have a profitable exploitation of wind power with thermal power the power capacities have to be conveniently seized. For instance, if there is an excess of thermal power in the coordination in comparison with the seized one, eventually this power should be submitted as an isolated offer if better exploitation is achieved. The approach for solving the offering strategy and the self-scheduling problem allows to take a decision about this eventually isolated offer. 

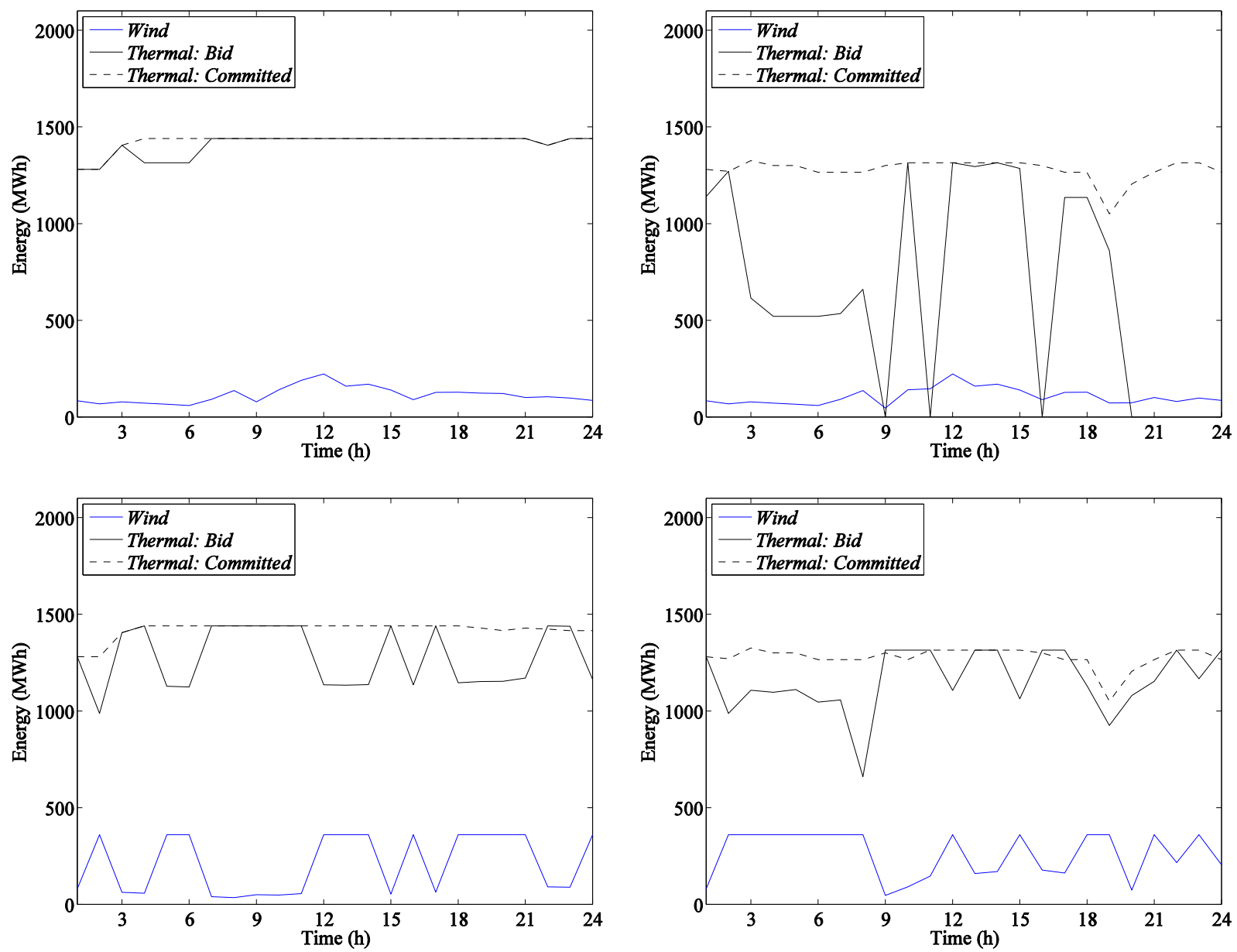

Fig. 7. Energy offer and committed. Top: uncoordinated; bottom: coordinated. Left: scenario 3, right: scenario 10.

Table 6

Gain variation in function of wind farm capacity.

\begin{tabular}{|c|c|c|c|}
\hline Wind farm (MW) & Expected uncoordinated profit $(€)$ & Expected coordinated profit $(€)$ & Gain (\%) \\
\hline 720 & 755247 & 766543 & 1.50 \\
\hline 1440 & 993646 & 1012520 & 1.90 \\
\hline 2160 & 1232045 & 1257004 & 2.03 \\
\hline 2880 & 1470444 & 1499547 & 1.98 \\
\hline 3600 & 1708843 & 1741753 & 1.93 \\
\hline 4320 & 1947242 & 1982611 & 1.82 \\
\hline
\end{tabular}

Table 7

Gain variation in function of the thermal units installed power

\begin{tabular}{|c|c|c|c|}
\hline Thermal units capacity (MW) & Expected uncoordinated profit $(€)$ & Expected coordinated profit $(€)$ & Gain (\%) \\
\hline 1340 & 585548 & 591942 & 1.09 \\
\hline 1240 & 531666 & 538657 & 1.31 \\
\hline 940 & 351366 & 357744 & 1.82 \\
\hline 890 & 318697 & 326988 & 2.60 \\
\hline 840 & 287759 & 296958 & 3.20 \\
\hline 780 & 252500 & 257529 & 1.99 \\
\hline
\end{tabular}

The stochastic programming is a suitable approach to address parameter uncertainty in modelling via scenarios. Hence, the proposed stochastic MILP approach proved both to be accurate and computationally acceptable, since the computation time scales up linearly with number of price scenarios, units and hours on the time horizon. Since the bids in the pool-based electricity market are made one day before, this approach is a helpful tool for the decision-maker. 


\section{Acknowledgements}

This work is funded by Portuguese Funds through the Foundation for Science and Technology-FCT under the project LAETA 2015-2020, reference UID/EMS/50022/2013.

\section{References}

[1] A.T. Al-Awami, M.A. El-Sharkawi, Coordinated trading of wind and thermal energy, IEEE Trans. Sustain. Energy 2 (3) (2011) 277-287.

[2] S. Pineda, A. Bock, Renewable-based generation expansion under a green certificate market, Renew. Energy 91 (2016) 53-63.

[3] I. Mignon, A. Bergek, Investments in renewable electricity production: the importance of policy revisited, Renew. Energy 88 (2016) 307-316.

[4] C. Gallego-Castillo, M. Victoria, Cost-free feed-in tariffs for renewable energy deployment in Spain, Renew. Energy 81 (2015) 411-420.

[5] J.M. Morales, A.J. Conejo, J. Perez-Ruiz, Short-term trading for a wind power producer, IEEE Trans. Power Syst. 25 (1) (2010) 554-564.

[6] C. Fernandes, P. Frías, J. Reneses, Participation of intermittent renewable generators in balancing mechanisms: a closer look into the Spanish market design, Renew. Energy 89 (2016) 305-316.

[7] Wind in Power: 2014 European Statistics, EWEA, February 2015. http://www. ewea.org/fileadmin/files/library/publications/statistics/EWEA-AnnualStatistics-2014.pdf.

[8] S. Nikolova, A. Causevski, A. Al-Salaymeh, Optimal operation of conventional power plants in power system with integrated renewable energy sources, Energy Convers. Manag. 65 (2013) 697-703.

[9] Key World Energy Statistics, International Energy Agency, 2014. http://www. iea.org/newsroomandevents/agencyannouncements/key-world-energystatistics-2014-now-available-for-free.html.

[10] L. Wu, M. Shahidehpour, T. Li, Stochastic security-constrained unit commitment, IEEE Trans. Power Syst. 22 (2) (2007) 800-811.

[11] R. Laia, H.M.I. Pousinho, R. Melicio, V.M.F. Mendes, Self-scheduling and bidding strategies of thermal units with stochastic emission constraints, Energy Convers. Manag. 89 (2015) 975-984.

[12] H.M.I. Pousinho, J.P.S. Catalão, V.M.F. Mendes, Offering strategies for a wind power producer considering uncertainty through a stochastic model, in: Proc. of International Conference on Probabilistic Methods Applied to Power Systems-PMAPS 2012, Istanbul, Turkey, 2012, pp. 1139-1144.

[13] S.K. Tong, S.M. Shahidehpour, Z. Ouyang, A heuristic short-term unit commitment, IEEE Trans. Power Syst. 6 (3) (1991) 1210-1216.

[14] Q.P. Zheng, J. Wang, A.L. Liu, Stochastic optimization for unit commitment-a review, IEEE Trans. Power Syst. 30 (4) (2015) 1913-1924.

[15] S. Najafi, Y. Pourjamal, A new heuristic algorithm for unit commitment problem, Energy Proc. 14 (2012) 2005-2011.

[16] C.K. Pang, G.B. Sheble, F. Albuyeh, Evaluation of dynamic programming based methods and multiple area representation for thermal unit commitments, IEEE Trans. Power Appar. Syst. 3 (1981) 1212-1218. PAS-100.

[17] A. Merlin, P. Sandrin, A new method for unit commitment at Electricite de France, IEEE Trans. Power Appar. Syst. 5 (1983) 1218-1225. PAS-102.

[18] H. Duo, H. Sasaki, T. Nagata, H. Fujita, A solution for unit commitment using Lagrangian relaxation combined with evolutionary programming, Electr. Power Syst. Res. 51 (1) (1999) 71-77.

[19] A. Trivedi, D. Srinivasan, S. Biswas, T. Reindl, Hybridizing genetic algorithm with differential evolution for solving the unit commitment scheduling problem, Swarm Evol. Comput. 23 (2015) 50-64.

[20] K. Abookazemi, H. Ahmad, A. Tavakolpour, M.Y. Hassan, Unit commitment solution using an optimized genetic system, Electr. Power Energy Syst. 33 (4) (2011) 969-975.

[21] T. Senjyu, K. Shimabukuro, K. Uezato, T. Funabashi, A fast technique for unit commitment problem by extended priority list, IEEE Trans. Power Syst. 18 (2) (2003) 882-888.

[22] R. Laia, H.M.I. Pousinho, R. Melício, V.M.F. Mendes, A.H. Reis, Schedule of thermal units with emissions in a spot electricity market, in: L.M. CamarinhaMatos, S. Tomic, P. Graça (Eds.), Technological Innovation for the Internet of Things, Springer, Heidelberg, 2013, pp. 361-370.

[23] R. Laia, H.M.I. Pousinho, R. Melício, V.M.F. Mendes, M. Collares-Pereira, Stochastic unit commitment problem with security and emissions constraints, in: L.M. Camarinha-Matos, N.S. Barreto, R. Mendonça (Eds.), Technological
Innovation for Collective Awareness Systems, Springer, Heidelberg, 2014, pp. 388-397.

[24] F. Zhuang, F.D. Galiana, Towards a more rigorous and practical unit commitment by Lagrangian relaxation, IEEE Trans. Power Syst. 3 (2) (1988) 763-773.

[25] Z. Ouyang, S.M. Shahidehpour, A multi-stage intelligent system for unit commitment, IEEE Trans. Power Syst. 7 (2) (1992) 639-646.

[26] S.A. Kazarlis, A.G. Bakirtzis, V. Petridis, A genetic algorithm solution to the unit commitment problem, IEEE Trans. Power Syst. 11 (1) (1996) 83-92.

[27] J.S. Dhillon, D.P. Kothari, Economic-emission load dispatch using binary successive approximation-based evolutionary search. IET Generation, Transm. Distrib. 3 (1) (2009) 1-16.

[28] K.P. Wong, C.C. Fung, Simulated annealing based economic dispatch algorithm, IEE Proc. C Gen., Transm. Distrib. 140 (6) (1993) 509-515.

[29] J. Ostrowski, M.F. Anjos, A. Vannelli, Tight mixed integer linear programming formulations for the unit commitment problem, IEEE Trans. Power Syst. 27 (1) (2012) 39-46.

[30] C.A. Floudas, X. Lin, Mixed integer linear programming in process scheduling: modeling, algorithms, and applications, Ann. Oper. Res. 139 (1) (2005) $131-162$.

[31] T.H.M. El-Fouly, H.H. Zeineldin, E.F. El-Saadany, M.M.A. Salama, Impact of wind generation control strategies, penetration level and installation location on electricity market prices, IET Renew. Power Gener. 2 (3) (2008) 162-169.

[32] J.L. Angarita, J. Usaola, J. Martinez-Crespo, Combined hydro-wind generation bids in a pool-based electricity market, Electr. Power Syst. Res. 79 (7) (2009) 1038-1046.

[33] G.N. Bathurst, G. Strbac, Value of combining energy storage and wind in shortterm energy and balancing markets, Electr. Power Syst. Res. 67 (1) (2003)1-8.

[34] J. García-Gonzalez, R.M.R. de la Muela, L.M. Santos, A.M. Gonzalez, Stochastic joint optimization of wind generation and pumped-storage units in an electricity market, IEEE Trans. Power Syst. 23 (2) (2008) 460-468.

[35] K.W. Hedman, G.B. Sheble, Comparing hedging methods for wind power: using pumped storage hydro units vs options purchasing, in: Proc. of International Conference on Probabilistic Methods Applied to Power Systems-PMAPS 2006, Stockolm, Sweden, 2006, pp. 1-6.

[36] G.N. Bathurst, J. Weatherill, G. Strbac, Trading wind generation in short term energy markets, IEEE Trans. Power Syst. 17 (3) (2002) 782-789.

[37] J. Matevosyan, L. Soder, Minimization of imbalance cost trading wind power on the short-term power market, IEEE Trans. Power Syst. 21 (3) (2006) 1396-1404.

[38] P. Pinson, C. Chevallier, G.N. Kariniotakis, Trading wind generation from shortterm probabilistic forecasts of wind power, IEEE Trans. Power Syst. 22 (3) (2007) 1148-1156.

[39] R. Laia, H.M.I. Pousinho, R. Melício, V.M.F. Mendes, M. Collares-Pereira, Offering strategies of wind power producers in a day-ahead electricity market, in: L.M. Camarinha-Matos, T.A. Baldissera, G. Di Orio, F. Marques (Eds.), Technological Innovation for Cloud-based Engineering Systems, Springer, Heidelberg, 2014, pp. 385-394.

[40] P.A. Ruiz, C.R. Philbrick, P.W. Sauer, Wind power day-ahead uncertainty management through stochastic unit commitment policies, in: Proc. IEEE/PES Power Systems Conference and Exposition-PSCE'09, Seattle, USA, 2009, pp. $1-9$.

[41] F. Shu, J.R. Liao, R. Yokoyama, C. Luonan, L. Wei-Jen, Forecasting the wind generation using a two-stage network based on meteorological information, IEEE Trans. Energy Convers. 24 (2) (2009) 474-482.

[42] A. Kusiak, Z. Haiyang, S. Zhe, Short-term prediction of wind farm power: a data mining approach, IEEE Trans. Energy Convers. 24 (1) (2009) 125-136.

[43] J.P.S. Catalão, H.M.I. Pousinho, V.M.F. Mendes, An artificial neural network approach for short-term wind power forecasting in Portugal, Eng. Intell. Syst. 1 (2009) 5-11.

[44] J.P.S. Catalão, S.J.P.S. Mariano, V.M.F. Mendes, L.A.F.M. Ferreira, Short-term electricity prices forecasting in a competitive market: a neural network approach, Electr. Power Syst. Res. 77 (10) (2007) 1297-1304.

[45] L.S. Coelho, A.A.P. Santos, A RBF neural network model with GARCH errors: application to electricity price forecasting, Electr. Power Syst. Res. 81 (1) (2011) 74-83.

[46] N. Amjady, A. Daraeepour, Mixed price and load forecasting of electricity markets by a new iterative prediction method, Electr. Power Syst. Res. 79 (9) (2009) 1329-1336.

[47] A.J. Conejo, M. Carrión, J.M. Morales, Decision making under uncertainty in electricity markets, in: International Series in Operations Research and Management Science, Springer, 2010. 